\title{
2017-2018 Türkiye Kar Sezonu İçin MODIS Etkili Kar Örtüsü Ürününün Sentinel 2 Görüntüleriyle Doğrulaması
}

\author{
Uğur TUTTU ${ }^{1}$, Semih KUTER ${ }^{2 *}$ \\ ${ }^{1}$ Çankırı Karatekin Üniversitesi, Fen Bilimleri Enstitüsü, Orman Mühendisliği Anabilim Dalı,18200, ÇANKIRI \\ ${ }^{2 *}$ Çankırı Karatekin Üniversitesi, Orman Fakültesi, Orman Mühendisliği Bölümü,18200, ÇANKIRI
}

\section{Öz}

$\mathrm{Bu}$ çalışmanın ana amacı Orta Çözünürlüklü Görüntüleme Spektroradyometresi (Moderate Resolution Imaging Spectroradiometer - MODIS)'ne ait etkili kar kaplı alan (EKKA) ürününün Türkiye üzerinde sürekli doğrulama çalışmalarının yapılabilmesi amacıyla Sentinel 2 uydu görüntülerinin uygunluğunun değerlendirilmesidir. Çalışmanın ilk aşamasında, üç farklı ikili kar haritalama algoritması uygulanarak elde edilen Sentinel 2 ikili kar örtüsü haritaları, yer istasyonlarından elde edilen kar derinliği ölçümleri ile test edilmiştir. Sentinel 2 ikili kar haritalarının performansını değerlendirmek için Kasım 2017 ile Nisan 2018 arasında çekilen 205 Sentinel 2 görüntüsü ile 75 yer gözlem istasyonundan alınan 286 kar derinliği ölçümü kullanılmıştır. Üç farklı ikili kar haritalama algoritmasının, $\mathrm{POD} \geq 0,86, \mathrm{FAR} \leq 0,08$ ve $\mathrm{ACC} \geq 0,82$ değerleri ile saha bazlı kar derinliği verileriyle yüksek uyum içinde olduğu tespit edilmiştir. İkinci aşamada, 2017-2018 Türkiye kar sezonuna ait 206 MODIS EKKA görüntüsü, Sentinel 2 ikili kar haritalarından elde edilen referans EKKA haritaları kullanılarak test edilmiştir. Analizlerde kullanılan Sentinel 2 görüntüler, bulutluluk oranı maksimum $\% 30$ olacak şekilde seçilmiş̧ir. Genel sonuçlar, MODIS EKKA ürünü olan MOD10A1'in RMSE $=0,13$ ve $R=0,88$ değerleri ile oldukça iyi bir performans sergilediğini göstermiştir. Ay bazlı performans metrikleri analiz edildiğinde, MOD10A1 ürününün doğruluğunun Nisan ayında düştüğü ve bu davranışın temel olarak erime süresi boyunca yamalı kar örtüsüne bağlandığı gözlenmiştir. Buna ek olarak, MOD10A1'in ormanlık alanlarda daha düşük performans sergilediği, ancak makilik ve karışık tarım arazilerinin hakim olduğu alanlarda doğruluğunun yüksek olduğu bulunmuştur.

Anahtar Kelimeler: Sentinel 2, MODIS, fraksiyonel kar örtüsü, uzaktan algılama, Türkiye.

\section{Validation of MODIS Fractional Snow Cover Product for 2017-2018 Snow Season in Turkey by using Sentinel 2 Imagery}

\begin{abstract}
This study mainly focuses on investigating the suitability of Sentinel 2 data for the continuous validation efforts of fractional snow cover (FSC) product of Moderate Resolution Imaging Spectroradiometer (MODIS) over Turkey. In the first stage of the study, Sentinel 2 binary snow cover maps obtained by applying three different binary snow mapping algorithms were tested against in-situ snow depth measurements. In total, 205 Sentinel 2 images taken between November 2017 and April 2018, 286 snow depth measurement from 75 ground observation stations were used to assess the performance of Sentinel 2 binary snow maps. All three binary snow mapping algorithms were in good agreement with in-situ snow depth data with POD $\geq 0.86, F A R \leq 0.08$ and ACC $\geq 0.82$. In the second stage, 206 MODIS FSC images for the 2017-2018 snow season over Turkey were tested by using reference FSC maps generated from Sentinel 2 binary snow maps. Sentinel 2 images used in the analyzes were selected so that the cloud contamination rate on each scene was maximum $30 \%$. Overall results indicated that MODIS FSC product, namely, MOD10A1 exhibited quite good performance with RMSE $=0.13$ and $R=0.88$. When the monthly-based performance metrics were analyzed it was observed that the accuracy of MOD10A1 product degraded in April and this behavior was mainly attributed to the patchy snow cover during the melting period. Additionally, MOD10A1 was found to exhibit poorer performance over forested areas, whereas its accuracy was high over areas dominated by savannas and mixed agricultural lands.
\end{abstract}

Keywords: Sentinel 2, MODIS, fractional snow cover, remote sensing, Turkey. 


\section{Giriş}

Temel bir iklim değişkeni olarak kabul edilen kar örtüsünün mekânsal ve zamansal kapsamı hidrolojik, meteorolojik ve çevresel süreçlerin çoğunda önemli bir rol oynar (Hüsler vd., 2012). Bu nedenle, kar örtüsünün mekânsal ve zamansal dağılımının sürekli olarak izlenmesi yerel ve küresel ölçekte mevcut ve gelecekteki iklimsel ve hidrolojik döngüler ile ekolojik dinamiklerin daha iyi anlaşılması bakımından kritik öneme sahiptir (Appel, 2018; Pirazzini vd., 2018).

Otomatik saha ölçümleri kar örtüsünün zamansal gelişimiyle ilgili sürekli ve doğrudan veri sağlamakla birlikte genellikle ölçümün yapıldığı sahaya bağımlıdırlar ve rüzgar, bitki örtüsü ve benzeri etkileşimlerden dolayı bozulmalara açıtırlar. Ayrıca bu tarz ölçümler ölçüm ağının yoğunluğuna göre iklim ve arazideki heterojenliklerden dolayı kar kütlesindeki mekânsal değişkenlikleri yakalamakta çok başarılı değildirler (LópezMoreno vd., 2013; Raleigh vd., 2016). Büyük ölçekli saha ölçümlerinin toplanmasında çoğunlukla istenilen mekânsal ölçüm yoğunluğuna ulaşılamamakta ve bu durum özellikle yüksek işletme maliyeti gerektiren zorlu çevre koşullarının hüküm sürdüğü dik eğimli, yüksek irtifalı ve uzak alanlarda ölçüm yapılamamasına neden olmaktadır (Viviroli vd., 2011).

Görünür ve yakın-kızılötesi dalga boylarındaki yüksek, kısa- ve orta-kızılötesi dalga boylarındaki düşük albedosu sayesinde kar örtüsü uzaktan algılama (UA) yolu ile 60'lı yılların ortalarından bu yana farklı operasyonel ve teknik özelliklerdeki düşük ve orta mekânsal çözünürlüğe sahip sensörlerce elde edilen çoklu spektral verilerle izlenebilmektedir (Hall ve Martinec, 1985). Karla ilgili parametrelerin UA ile elde edilmesi dolaylı bir ölçüm yöntemi olduğundan doğruluklarının nicel olarak değerlendirilmesi gerekmektedir (Dong ve Peters-Lidard, 2010; Frei vd., 2012). Bu nedenle UA tabanlı kar ürünlerinin kapsamlı bir şekilde doğrulanarak güvenilirliklerinin doğru bir şekilde ölçülerek değerlendirilmesi, olası hataların belirlenmesi ve UA yolu ile kar ürünü elde etmekte kullanılan algoritmaların iyileştirilmesine yönelik çalışmalar açısından önem arz etmektedir. Düşük ve orta mekânsal çözünürlüklü uydu görüntülerinden elde edilen çeşitli kar örtüsü ürünleri için algoritma geliştirme ve doğrulama çalışmalarında yüksek çözünürlüklü uydu görüntülerinin kullanılması genel kabul gören yaygın bir uygulamadır (Crawford, 2015; Metsämäki vd., 2016; Salomonson ve Appel, 2004; Sürer ve Akyürek, 2012).

$\mathrm{Bu}$ çalışmanın temel amacı Orta Çözünürlüklü Görüntüleme Spektroradyometresi (Moderate Resolution Imaging Spectroradiometer - MODIS) verisinden elde edilen etkili kar kaplı alan (EKKA) ürünü olan MOD10A1'in (Riggs ve Hall, 2016) 2017-2018 kar sezonu için Türkiye’de Sentinel 2 görüntüleriyle doğrulamasının yapılmasıdır. MODIS $0,4 \mu \mathrm{m}-14,4 \mu \mathrm{m}$ dalga boyu aralığında sahip olduğu üç farklı mekânsal çözünürlükteki 36 spektral bantı ve bir günlük zamansal çözünürlüğü ile bölgesel ve küresel ölçekte kar örtüsü haritalaması amacıyla oldukça yaygın olarak kullanılan bir araçtır (Hall vd., 2002; Parajka ve Blöschl, 2008; Poon ve Valeo, 2006; Rodell ve Houser, 2004; Shamir ve Georgakakos, 2006; Wang vd., 2008). Avrupa Uzay Ajansı (European Space Agency - ESA) tarafindan işletilmekte olan Sentinel 2 uydusu; 443 nm - 2243 nm aralığında 10, 20 ve 60 m olmak üzere üç farklı mekânsal çözünürlükte toplam 13 spektral banta sahiptir.

Çalışmanın ilk aşamasında Sentinel 2 görüntülerinden üç farklı algoritma ile ikili kar haritaları üretilerek bu haritaların doğruluğu Meteoroloji Genel Müdürlüğü (MGM) tarafından işletilen yer ölçüm istasyonlarından alınan günlük kar derinliği (KD) ölçümleri kullanılarak değerlendirilmiştir. Çalışmanın ikinci aşamasında ise 2017-2018 kar sezonuna ait MODIS EKKA ürünü olan MOD10A1 görüntülerinin doğruluğu daha yüksek mekânsal çözünürlüğe sahip Sentinel 2 verisinden üretilen referans EKKA haritaları kullanılarak test edilmiştir. Çalışmanın kalan kısmı şu şekilde düzenlenmiştir: Çalışmada kullanılan materyal ve yöntem 2. Bölümde verilmiştir. 3. Bölümde çalışma sonucunda elde edilen bulgular ve sonuçlarla ilgili tartışma sunulmaktadır. Son olarak, çalışmada elde edilen genel bulgular ve sonuçlar 4. Bölümde kısaca özetlenerek, gelecekteki potansiyel çalışma konuları ile ilgili özet bilgiler aktarılmıştır.

\section{Materyal ve Metot}

\subsection{Sentinel 2 Görüntü Verisi ve İkili Kar Haritalarının Oluşturularak Doğrulanması}

Sentinel 2 Avrupa Uzay Ajansı (European Space Agency - ESA) tarafindan kara, okyanus ve atmosferin izlenmesi amacıyla geliştirilen ve işletilen çok spektralı bir görüntüleyicinin adıdır (Gatti ve Galoppo, 2018). Zamansal çözünürlük ve kapsama alanı koşullarının yerine getirilmesi amacıyla sistem Sentinel 2A ve 2B olmak üzere birbirinin aynısı iki uydudan oluşmaktadır. Sentinel 2A ve 2B'ye ait spektral bantlar Tablo 1'de verilmiştir. 
Tablo 1. Sentinel 2A ve 2B spektral bantlar.

\begin{tabular}{lccc}
\hline $\begin{array}{c}\text { Spektral } \\
\text { Bant }\end{array}$ & $\begin{array}{c}\text { 2A Merkez } \\
\text { Dalga Boyu } \\
\text { (nm) }\end{array}$ & $\begin{array}{c}\text { 2B Merkez } \\
\text { Dalga Boyu } \\
\text { (nm) }\end{array}$ & $\begin{array}{c}\text { Mekânsal } \\
\text { Çözünürlük } \\
\text { (m) }\end{array}$ \\
\hline Bant 1 & 442,7 & 442,2 & 60 \\
Bant 2 & 492,4 & 492,1 & 10 \\
Bant 3 & 559,8 & 559,0 & 10 \\
Bant 4 & 664,6 & 664,9 & 10 \\
Bant 5 & 704,1 & 703,8 & 20 \\
Bant 6 & 740,5 & 739,1 & 20 \\
Bant 7 & 782,8 & 779,7 & 20 \\
Bant 8 & 832,8 & 832,9 & 10 \\
Bant 8A & 864,7 & 864,0 & 20 \\
Bant 9 & 945,1 & 943,2 & 60 \\
Bant 10 & 1373,5 & 1376,9 & 60 \\
Bant 11 & 1613,7 & 1610,4 & 20 \\
Bant 12 & 2202,4 & 2185,7 & 20 \\
\hline
\end{tabular}

Sentinel 2 ikili kar haritaları (kar/kar değil) üç farklı ikili kar sınıflandırma algoritması kullanılarak elde edilmiştir. Kullanılan ilk algoritma orijinal MODIS ikili kar haritalama algoritmasının (Hall vd., 1995) eşdeğeri olup yoğun ormanlık olmayan bir Sentinel 2 pikselinin kar olarak sınıflandırılabilmesi için bant 3 ve bant 11 reflektans değerlerinden üretilen ve Eşitlik 1'de verilen normalize fark kar indisi (normalized difference snow index - NDSI) değerinin $\geq 0,4$, bant 3 reflektans değerinin $\geq \% 10$ ve bant 8 A reflektans değerinin $>\% 11$ olmas 1 koşullarının aynı anda sağlanması gerekmektedir.

$$
\mathrm{NDSI}_{\text {Sentinel } 2}=\frac{\text { bant } 3-\text { bant } 11}{\text { bant } 3+\text { bant } 11}
$$

İkinci algoritma (Hall vd., 1998) birinci algoritmanın geliştirilmiş versiyonu olup yoğun ormanlık alanlarda kar sınıflandırma doğruluğunu arttırmak amacıyla ilk algoritmada bir pikselin kar olarak sınıflandırılabilmesi için istenilen koşullara ek olarak düzensiz bir NDSI - normalize fark vejetasyon indisi (normalized difference vegetation index - NDVI, Bkz. Eşitlik 2) karar bölgesi koşulu getirilmiştir (Bkz. Şekil 1).

$$
\mathrm{NDVI}_{\text {Sentinel } 2}=\frac{\text { bant8A }- \text { bant } 4}{\text { bant8A }+ \text { bant } 4} \text {. }
$$

İkili kar haritalarının üretilmesinde kullanılan üçüncü algoritma ise ESA tarafindan sağlanan ve Sentinel 2 Seviye-2A sınıflandırılmış görüntünün elde edilmesi için kullanılan Sen2Cor v2.5.5 modülüdür (Louis vd., 2016). Sen2Cor on ana modülden oluşmakta olup optimal olarak düzeltilmiş atmosfer altı reflektans görüntüleri oluşturmak için Sentinel 2 Seviye-1C giriş verilerinin atmosferik, arazi ve sirüs bulut düzeltme işlemlerini yapabilmektedir (Louis, 2018). Sen2Cor v.2.5.5 arazi sınıfları Tablo 2'de verilmiştir. Bu üç algoritma kullanılarak elde edilen Sentinel 2 ikili kar haritaları 20 m mekânsal çözünürlüğe sahiptir.

$\mathrm{Bu}$ çalışmanın önemli ve gerekli bir aşaması üç farklı algoritma uygulanarak oluşturulan ve referans EKKA haritalarının üretilmesinde kullanılacak olan Sentinel 2 ikili kar haritalarının doğruluğunu analiz etmektir. Sentinel 2 ikili kar haritalarının doğruluğunu değerlendirmek için, Meteoroloji Genel Müdürlüğü (MGM) tarafından işletilen otomatik meteoroloji istasyonlarından (AWOS: Otomatik Hava Gözlem Sistemi Automated Weather Observing System ve SPA: Kar Kütle Analizörü - Snow Pack Analyser) elde edilen kar verileri kullanılmış, günlük KD değerleri, bu istasyonlardan gelen ham verilerin işlenmesi ve filtrelenmesi yoluyla elde edilmiştir. İkili kar haritalarının doğruluk analizlerinde 75 yer istasyonundan elde edilen KD ölçümleri ve Kasım 2017 ile Nisan 2018 arasında alınan 205 Sentinel 2 görüntüsü kullanılmıştır. Yer istasyonları ve Sentinel 2 karoların konumları Şekil 2'de verilmiştir. Sentinel 2 ikili kar haritalarının yer tabanlı verilere göre doğrulamasında URL-1 (2008)'de belirtilen prosedür baz alınmıştır. Yer tabanlı yapılan ölçümlere göre, 5 cm'lik KD eşiği aşıldığında ilgili piksel "kar" olarak, KD değeri 5 cm'nin altında ise "kar değil”" olarak etiketlenmektedir. 


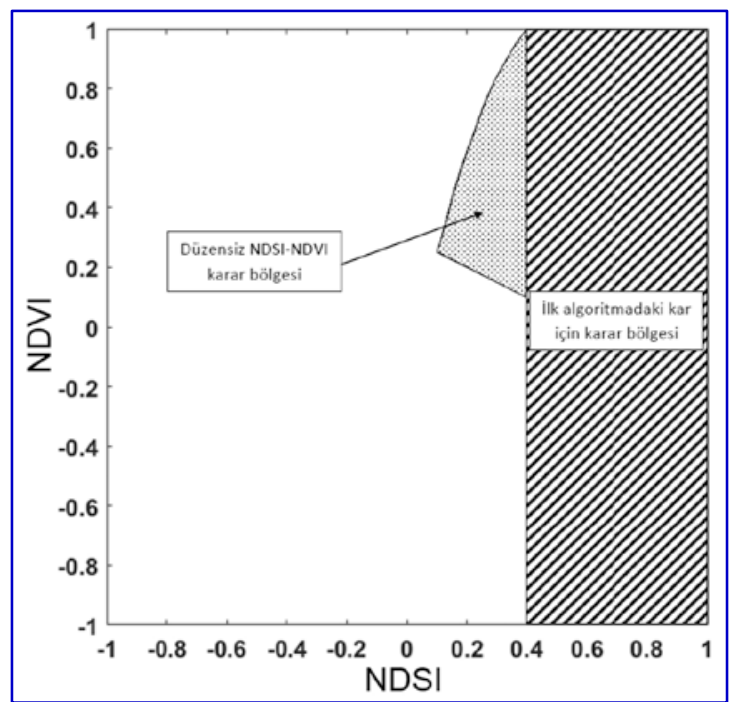

Şekil 1. İkinci algoritmada kullanılan düzensiz NDSI-NDVI karar bölgesi (Hall vd. (1998)'den uyarlanmıştır).

Tablo 2. Sen2Cor arazi sınıfları.

\begin{tabular}{cl}
\hline Etiket & \multicolumn{1}{c}{ Sınıf } \\
\hline $\mathbf{0}$ & Veri yok \\
$\mathbf{1}$ & Doygun/Kötü \\
$\mathbf{2}$ & Koyu alan \\
$\mathbf{3}$ & Bulut gölgesi \\
$\mathbf{4}$ & Vejetasyon \\
$\mathbf{5}$ & Vejetasyon yok \\
$\mathbf{6}$ & Su \\
$\mathbf{7}$ & Sinıflandırılmamış \\
$\mathbf{8}$ & Bulut (orta olasıllklı) \\
$\mathbf{9}$ & Bulut (yüksek olasılıkl1) \\
$\mathbf{1 0}$ & İnce sirüs \\
$\mathbf{1 1}$ & Kar \\
\hline
\end{tabular}

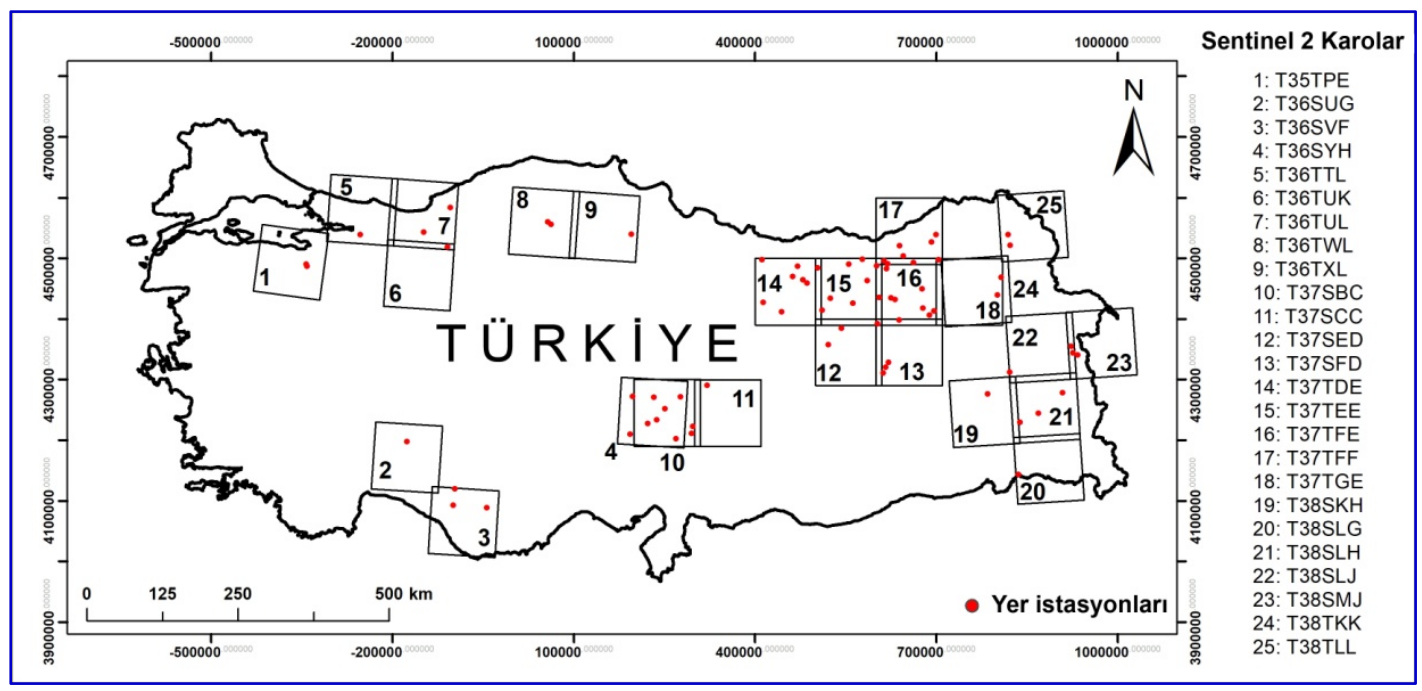

Şekil 2. Sentinel 2 ikili kar haritalarının doğruluk analizinde kullanılan yer istasyonları ve Sentinel 2 karoların konumlar1.

Sentinel 2 ikili kar haritalarının yer verisiyle karşılaştırılmasında Tablo 3 'te verilen hata matrisi ve bu matristen üretilen aşağıdaki performans değerlendirme metrikleri kullanılmıştır (Doswell III vd., 1990): 
- $\quad$ Algılama olasılığ - Probability of detection $(P O D)=A /(A+C)$,

- Yanlış alarm oranı - False alarm ratio $(F A R)=B /(A+B)$,

- Yanlış algılama olasılı̆̆ı - Probability of false detection (POFD) = B/(B+D),

- Doğruluk - Accuracy $(A C C)=(A+D) /(A+B+C+D)$,

- Kritik başarı endeksi - Critical success index $(C S I)=A /(A+B+C)$,

- Heidke puanı - Heidke skill score $(H S S)=2(A D-B C) /[(A+C)(C+D)+(A+B)(B+D)]$.

Tablo 3. İkili hata matrisi.

\begin{tabular}{|c|c|c|c|c|}
\hline & & \multicolumn{2}{|c|}{ Yer İstasyon Verisi } & \\
\hline & & kar & kar değil & \\
\hline \multirow{3}{*}{ 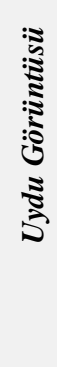 } & kar & $\begin{array}{c}\text { ISABET } \\
\text { (HITS) } \\
\text { A }\end{array}$ & $\begin{array}{c}\text { HATALI ALARM } \\
\text { (FALSE ALARMS) } \\
\text { B }\end{array}$ & $\begin{array}{l}\text { İSABET + } \\
\text { HATALI } \\
\text { ALARM }\end{array}$ \\
\hline & kar değil & $\begin{array}{l}\text { KAÇAN } \\
\text { (MISSES) } \\
\text { C }\end{array}$ & $\begin{array}{c}\text { DOĞRU NEGATIFLER } \\
\text { (CORRECT NEGATIVES) } \\
\text { D }\end{array}$ & $\begin{array}{c}\text { KAÇAN + } \\
\text { DOĞRU } \\
\text { NEGATİFLER }\end{array}$ \\
\hline & & İSABET + KAÇAN & $\begin{array}{l}\text { HATALI ALARM + DOĞRU } \\
\text { NEGATİFLER }\end{array}$ & \\
\hline
\end{tabular}

\subsection{MODIS MOD10A1 Verisinin Ön İşlenmesi ve Referans EKKA Haritalarının Üretilmesi}

MOD10A1 EKKA ürünü, daha yüksek mekânsal çözünürlüklü Landsat kar haritalarından üretilen referans EKKA haritaları kullanılarak bir MODIS pikselindeki fraksiyonel kar miktarı ile NDSI değeri arasında istatistiksel bir doğrusal ilişki kurularak elde edilmektedir (Salomonson ve Appel, 2004, 2006). Bu yöntem şu anda MODIS Koleksiyon 5 ve 6'da (C5 ve C6) sunulan 500 m mekânsal çözünürlükteki standart EKKA ürününü üretmek için kullanılmaktadır. C6'daki kar örtüsü EKKA değeri yerine NDSI kar örtüsü olarak verilmektedir. Dolayısıyla, Salomonson ve Appel (2006)'daki EKKA denklemi (Bkz. Eşitlik 3), C6'da verilen NDSI kar örtüsü verilerine uygulanarak EKKA değeri hesaplanmaktadır (Riggs vd., 2016).

$$
\mathrm{EKKA}=-0,01+1,45 * \text { NDSI. }
$$

MOD10A1 ürününün 2017-2018 Türkiye kış sezonu için doğrulanması amacıyla Kasım 2017 - Nisan 2018 arasında çekilen toplam 206 Sentinel 2 - MOD10A1 görüntü çifti kullanılmıştır (Bkz. Tablo 4). Tüm Sentinel 2 karolar bulutluluk oranı en fazla \%30 olacak şekilde seçilmiştir. MODIS MOD10A1 görüntüleri, ilgili Sentinel 2 görüntülerinin projeksiyonuyla eşleşmesi için WGS84 referanslı ortak bir UTM projeksiyonuna MODIS projeksiyonlandırma aracı (MODIS Reprojection Tool) (Dwyer ve Schmidt, 2006) kullanılarak yeniden projeksiyonlandırılmıştır. Bulutlu, bulut gölgesi, su ve kötü kaliteli pikseller, MODIS MOD09 kalite verisinden (Vermote vd., 2011) elde edilen mekânsal maskeler yardımıyla analizlerden çıkarılmıştır.

Referans EKKA haritaları, 500 m mekânsal çözünürlükteki tam bir MODIS MOD10A1 pikseli içine düşen 20 m mekânsal çözünürlükteki Sentinel 2 kar piksellerinin ortalaması alınarak oluşturulmuştur (Bkz. Şekil 3). Orijinal MOD10A1 haritalarının Sentinel 2'den üretilen referans EKKA haritalarıyla karşılaştırılmasında hataların kareleri ortalamasının karekökü (Root Mean Squared Error - RMSE) ve Pearson korelasyon katsayısı $(R)$ performans metrikleri kullanılmıştır:

$$
\mathrm{RMSE}=\sqrt{\frac{\sum_{i=1}^{N}\left(\hat{y}_{i}-y_{i}\right)^{2}}{N}}, R=\frac{N \sum_{i=1}^{N} y_{i} \hat{y}_{i}-\sum_{i=1}^{N} y_{i} \sum_{i=1}^{N} \hat{y}_{i}}{\sqrt{N \sum_{i=1}^{N} y_{i}^{2}-\left(\sum_{i=1}^{N} y_{i}\right)^{2}} \sqrt{N \sum_{i=1}^{N} \hat{y}_{i}^{2}-\left(\sum_{i=1}^{N} \hat{y}_{i}\right)^{2}}} .
$$

İfade (4)'de, $N$ toplam gözlem sayısını, $y_{i}$, i. gözleme ait referans değerini, ve $\hat{y}_{i}$ ise $i$. gözleme ait tahmin edilen değeri belirtmektedir. 
Tablo 4. MODIS MOD10A1 - Sentinel 2 görüntü çiftleri.

\begin{tabular}{cccccccc}
\hline Sentinel & \multirow{2}{*}{ Karo } & \multicolumn{6}{c}{ MODIS - Sentinel 2 Görüntü Sayıları } \\
\cline { 2 - 8 } No & Sayısı & Kasım & Aralık & Ocak & Şubat & Mart & Nisan \\
\hline T35TPE & 7 & - & - & 3 & - & 1 & 3 \\
T36SUG & 7 & - & - & 2 & 2 & - & 3 \\
T36SVF & 15 & 2 & 3 & 2 & 2 & 2 & 4 \\
T36SYH & 8 & - & 3 & - & 2 & 2 & 1 \\
T36TTL & 3 & - & 1 & 1 & - & - & 1 \\
T36TUK & 8 & - & 3 & 1 & 1 & - & 3 \\
T36TUL & 7 & - & 2 & - & 1 & 2 & 2 \\
T36TWL & 9 & - & 4 & 2 & - & 1 & 2 \\
T36TXL & 5 & - & 2 & - & - & - & 3 \\
T37SBC & 5 & - & 2 & - & 1 & 1 & 1 \\
T37SCC & 4 & - & 1 & 1 & - & 1 & 1 \\
T37SED & 11 & 2 & 2 & 2 & 2 & 1 & 2 \\
T37SFD & 17 & 2 & 5 & 3 & 2 & 2 & 3 \\
T37TDE & 4 & - & 2 & - & - & 1 & 1 \\
T37TEE & 10 & 2 & 2 & 1 & 2 & 1 & 2 \\
T37TFE & 12 & 1 & 4 & 1 & 2 & 1 & 3 \\
T37TFF & 6 & - & 2 & 1 & 2 & - & 1 \\
T37TGE & 6 & - & 3 & - & 1 & - & 2 \\
T38SKH & 9 & - & 3 & 1 & 2 & 1 & 2 \\
T38SLG & 10 & 2 & 2 & 1 & 2 & 1 & 2 \\
T38SLH & 16 & 2 & 5 & 1 & - & 2 & 6 \\
T38SMJ & 8 & - & 1 & 2 & 2 & - & 3 \\
T38TKK & 7 & - & 3 & - & 2 & - & 2 \\
T38TLL & 5 & - & 1 & - & 1 & - & 3 \\
T38SLJ & 7 & - & 1 & 1 & 1 & 1 & 3 \\
TOPLAM & $\mathbf{2 0 6}$ & $\mathbf{1 3}$ & $\mathbf{5 7}$ & $\mathbf{2 6}$ & $\mathbf{3 0}$ & $\mathbf{2 1}$ & $\mathbf{5 9}$ \\
\hline & & & & & & & \\
& & & & 2 & & & 2 \\
\end{tabular}




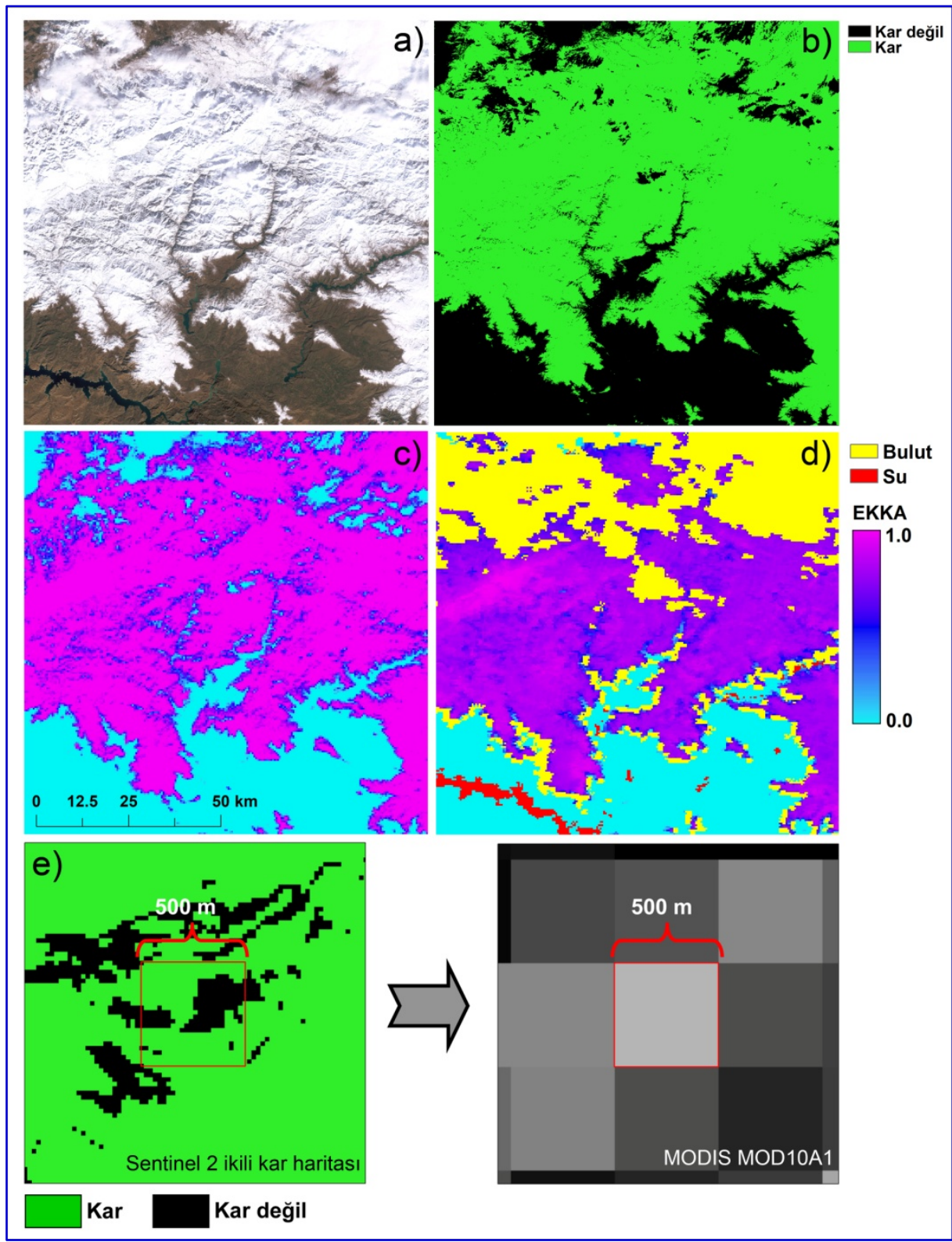

Şekil 3. 28 Ocak 2018 tarihli T37SED karosu için: a) gerçek renk RGB kompozit Sentinel 2 göüntüsü, b) Sentinel 2 ikili kar haritası, c) Sentinel 2 bazlı referans EKKA haritası, d) MOD10A1 görüntüsü, ve e) bir MODIS pikseli içine düşen Sentinel 2 ikili kar haritası pikselleri (Not: Bir MODIS pikseli içine $(500 \mathrm{~m})$ yaklaşık 530 Sentinel 2 pikseli $(20 \mathrm{~m})$ düşmektedir. Şekilde gösterilen alanda toplam 529 Sentinel 2 pikseli olup bunlardan 377 tanesi kar etiketlidir, dolayısı ile bu MODIS pikseli için referans EKKA değeri 0,71 olarak hesaplanmaktadır).

\subsection{MODIS MCD12Q1 Arazi Sınıfları Verisi}

Çalışmada MOD10A1 ürününün performansının arazi tipine bağlı değişimini incelemek amacıyla arazi kullanım sınıfları MODIS'e ait Uluslararası Jeosfer-Biyosfer Programı (International Geosphere Biosphere Programme-IGBP) çerçevesinde 2001 yilından itibaren MODIS reflektans verilerinin kontrollü sınıflandırması yoluyla yıllık olarak üretilen 500 m mekânsal çözünürlüğe sahip MCD12Q1 arazi örtüsü tipi ürününden elde edilmiştir (Friedl vd., 2010). Ürün toplamda 17 arazi tipinden oluşmakta olup, bu çalışmada benzer arazi tipleri birleştirilerek toplam 9 arazi sınıfına indirgenmiştir. Orijinal ve birleştirilmiş arazi sınıfları Tablo 5'de verilmiştir. Analizlerden önce, tüm MCD12Q1 karolar ilgili Sentinel 2 görüntülerin projeksiyonuyla eşleşmesi amacıyla ortak bir WGS84/UTM koordinat sistemine yeniden projeksiyonlandırılmıştır. 
Tablo 5. MCD12Q1 arazi tipi sinıfları.

\begin{tabular}{ll}
\hline \multicolumn{1}{c}{ Orjinal Sınıf } & \multicolumn{1}{c}{ Birleştirilmiş Sınıf } \\
\hline $\begin{array}{l}\text { Her dem yeşil iğne yapraklı orman } \\
\text { Her dem yeşil geniş yapraklı orman }\end{array}$ & Her mevsim yeşil orman \\
\hline $\begin{array}{l}\text { Yaprak döken iğne yapraklı orman } \\
\text { Yaprak döken geniş yapraklı orman }\end{array}$ & Yaprak döken orman \\
\hline Karışık orman & Karışık orman \\
\hline $\begin{array}{l}\text { Tarım arazisi } \\
\text { Kentsel alan } \\
\text { Tarım arazisi/doğal bitki örtüsü mozaiği }\end{array}$ & Karışık tarım \\
\hline Çorak/seyrek bitki örtüsü & Çorak/seyrek bitki örtüsü \\
\hline $\begin{array}{l}\text { Odunsu makilikler } \\
\text { Makilikler }\end{array}$ & Makilikler \\
\hline $\begin{array}{l}\text { Sik çalılıklar } \\
\text { Seyrek çalılıklar } \\
\text { Otlaklar }\end{array}$ & Çalılıklar/otlaklar \\
\hline Kalıcı sulak alanlar & Sulak alanlar \\
\hline $\begin{array}{l}\text { Kalıcı kar ve buz } \\
\text { Su }\end{array}$ & Kullanılmadı \\
\hline
\end{tabular}

\section{Bulgular ve Tartışma}

\subsection{Sentinel 2 Íkili Kar Haritalarının Yer Verisi ile Test Sonuçları}

Bölüm 2.2'de verilen üç farklı ikili kar haritalama algoritması kullanılarak elde edilen Sentinel 2 ikili kar haritalarının yer istasyon verilerinden elde edilen kar derinliği ölçümleriyle karşılaştırılması sonucunda Tablo 68'de verilen ikili hata matrisleri elde edilmekte olup, bu hata matrisleri kullanılarak hesaplanan ikili performans metrikleri de Tablo 9'da verilmektedir. Değerlendirmede toplam 286 gözlem olup, bunlardan 11 tanesinin bulut pikseli olduğu tespit edilerek ikili hata matrislerine dahil edilmemiştir.

Tablo 9'da verilen ikili performans metrikleri incelendiğinde; Sentinel 2 ikili kar haritaları için Algoritma 1'de; $\mathrm{POD}=0,8809$ ve $\mathrm{ACC}=0,8436$, Algoritma 2'de; $\mathrm{POD}=0,8894$ ve $\mathrm{ACC}=0,8436$ ile Algortima 3'de POD = 0,8590 ve $\mathrm{ACC}=0,8182$ olmaktadır. Bu metriklerin sonuçları Algoritma 2'nin performansının diğer iki algoritmaya göre yer ölçümlerinden elde edilen KD ölçümleri ile daha iyi uyum içinde olduğunu göstermektedir. Dolayısıyla, MODIS MOD10A1 ürününün doğrulama çalışmalarında kullanılacak referans EKKA haritaları Algoritma 2 kullanılarak üretilen Sentinel 2 ikili kar haritalarından elde edilmiştir.

Tablo 6. Algoritma 1 için ikili hata matrisi.

\begin{tabular}{|c|c|c|c|c|}
\hline \multirow{2}{*}{\multicolumn{2}{|c|}{ Algoritma 1}} & \multicolumn{2}{|c|}{ Yer İstasyon Verisi } & \\
\hline & & kar & kar değil & \\
\hline \multirow{3}{*}{ כ: } & kar & 207 & 15 & 222 \\
\hline & kar değil & 28 & 25 & 53 \\
\hline & & 235 & 40 & 275 \\
\hline
\end{tabular}


Tablo 7. Algoritma 2 için ikili hata matrisi.

\begin{tabular}{|c|c|c|c|c|}
\hline \multirow{2}{*}{\multicolumn{2}{|c|}{ Algoritma 1}} & \multicolumn{2}{|c|}{ Yer İstasyon Verisi } & \\
\hline & & kar & kar değil & \\
\hline \multirow{3}{*}{ కై } & kar & 209 & 17 & 226 \\
\hline & kar değil & 26 & 23 & 49 \\
\hline & & 235 & 40 & 275 \\
\hline
\end{tabular}

Tablo 8. Algoritma 3 için ikili hata matrisi.

\begin{tabular}{|c|c|c|c|c|}
\hline \multirow{2}{*}{\multicolumn{2}{|c|}{ Algoritma 1}} & \multicolumn{2}{|c|}{ Yer İstasyon Verisi } & \\
\hline & & kar & kar değil & \\
\hline \multirow{3}{*}{ 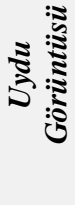 } & kar & 201 & 17 & 218 \\
\hline & kar değil & 33 & 24 & 57 \\
\hline & & 234 & 41 & 275 \\
\hline
\end{tabular}

Tablo 9. Üç farklı ikili kar sınıflandırma algoritmasına ait performans metrikleri.

\begin{tabular}{cccc}
\hline Metrik & Algoritma 1 & Algoritma 2 & Algoritma 3 \\
\hline POD & 0,8809 & $\mathbf{0 , 8 8 9 4}$ & 0,8590 \\
FAR & $\mathbf{0 , 0 6 7 6}$ & 0,0752 & 0,0780 \\
POFD & $\mathbf{0 , 3 7 5 0}$ & 0,4250 & 0,4146 \\
ACC & $\mathbf{0 , 8 4 3 6}$ & $\mathbf{0 , 8 4 3 6}$ & 0,8182 \\
CSI & 0,8280 & $\mathbf{0 , 8 2 9 4}$ & 0,8008 \\
HSS & $\mathbf{0 , 4 4 5 7}$ & 0,4247 & 0,3827 \\
\hline
\end{tabular}

Kullanılan üç algoritmada da FAR ve POFD değerleri sırasıyla 0,07 - 0,08 ile 0,38 - 0,43 aralığında olup Sentinel 2'den üretilen ikili kar haritalarında düşükte olsa sınıflandırma hatası olduğunu ortaya koymaktadır. Elde edilen ikili kar haritaları görsel olarak incelendiğinde, bu hatanın yer istasyonunun kar göstermediği durumda gerçekte bulut olan pikselin algoritma tarafından hatalı olarak kar şekilde sınıflandırılmasından kaynaklandığ 1 görülmüştür.

\subsection{MODIS MOD10A1 EKKA Ürününün Sentinel 2 Referans EKKA Haritaları ile Karşılaştırma Sonuçları}

Algoritma 2 kullanılarak üretilen referans EKKA haritalarıyla MOD10A1 ürününün karşılaştırılmasına tüm karolar ve tarihler bazında genel olarak bakıldığında ortalama RMSE ve $R$ değerleri sirasıyla 0,13 ve 0,88 olmaktadır. Düşük RMSE ve yüksek $R$ değerleri M0D10A1 ürününün Sentinel 2'den üretilen referans EKKA haritalarıyla yüksek uyum içerisinde olduğunu göstermektedir.

Bununla birlikte, ay bazında $R$ değerlerine bakıldığında (Bkz. Şekil 4) Kasım - Mart ayları için ortalama $R$ değerleri 0,89 - 0,95 aralığında olurken, Nisan ayı için ortalama 0,81 değeri ile düşüş göstermektedir. Bu durum benzer çalışmalarda da rapor edildiği gibi (Klein ve Barnett, 2003; Marchane vd., 2015; Tekeli vd., 2005) karın erimeye başladığı dönemde kar örtüsü yamalı (patchy snow cover) bir görüntü aldığından MODIS EKKA ürününün doğruluğunun düşüş göstermekte olduğunu ortaya koymaktadır.

Şekil 3d görsel olarak analiz edildiğinde, MOD10A1 ürününde kara-kar sınırındaki piksellerin bulut olarak tanımlandığı gözlemlenmektedir. Bu durumun Sentinel 2 ve MODIS'in geçiş zamanlarındaki farklılıktan mı kaynaklandığına bakıldığında ise bu iki uydunun geçiş zamanlarının çok yakın olduğu görülmektedir (Bkz. Tablo 10). Kara-kar sınırındaki karışık piksellerin (mixed pixels), özellikle yamalı ve sulu kar durumunda, MOD10A1 algoritmasın tarafından hatalı bir şekilde bulut olarak etiketlendiği anlaşılmakta olup bu durum literatürdeki benzer çalışmalarda da belirtilmektedir (Parajka ve Blöschl, 2006; Parajka vd., 2012; Parajka vd., 2010; Şorman vd., 2007; Wang vd., 2009). 
Şekil 5'de verilen karo bazlı RMSE ve $R$ bulgularına bakıldığında ortalama RMSE değerinin en yüksek 0,20'ye $R$ değerinin ise 0,95 'e ulaştığı görülmektedir. En düşük ortalama $R$ değeri 0.51 ile T36TTL karosuna ait olurken, T36TUK, T36TUL, T36TWL ve T35TPE karoları için ortalama $R$ değerleri 0,70 - 0,78 aralığındadır. T36SUG, T36TXL, T37TGE, T38SKH, T38SLG ve T38SLH karolarında ortalama $R$ değerleri 0,85 ile 0,89 arasında değişmektedir. Geriye kalan 14 adet karoda ise $R$ değerleri 0.90 'ın üzerindedir.

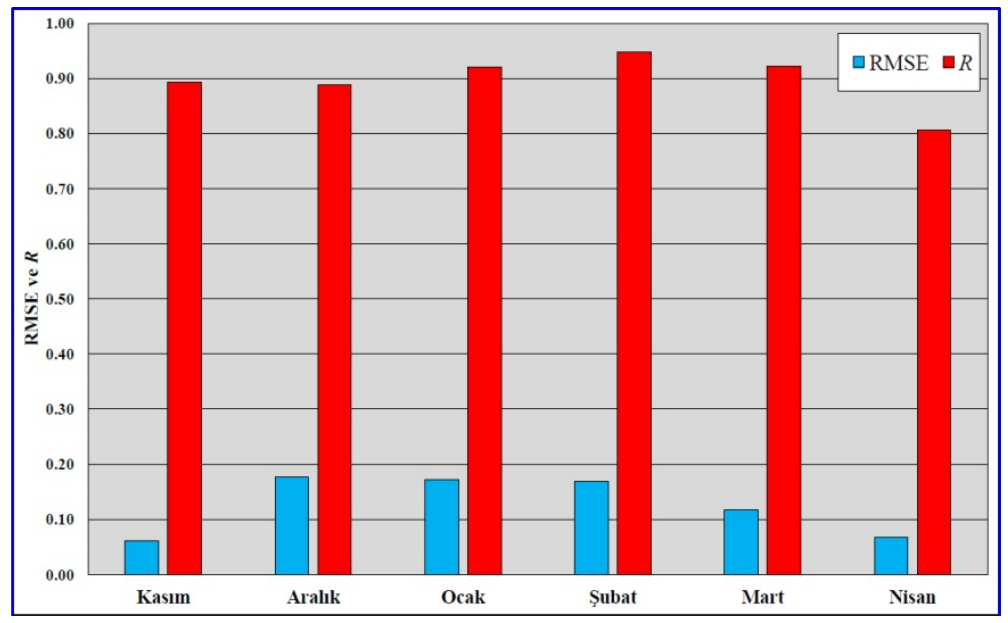

Şekil 4. MOD10A1 için ay bazında ortalama RMSE ve $R$ değerleri.

Tablo 10. Bazı karolarda Sentinel 2 - MODIS geçiş zamanları.

\begin{tabular}{lllll}
\hline Tarih & $\begin{array}{l}\text { Sentinel 2 } \\
\text { Karo No }\end{array}$ & $\begin{array}{l}\text { Sentinel 2 } \\
\text { Geçiş Zaman }\end{array}$ & $\begin{array}{l}\text { MODIS } \\
\text { Karo No }\end{array}$ & $\begin{array}{l}\text { MODIS } \\
\text { Geçiş Zamanı }\end{array}$ \\
\hline 5 Nisan 2018 & T35TPE (2A) & $8: 46: 01$ & h20v05 & $8: 30: 00$ \\
10 Mart 2018 & T36TWL (2A) & $8: 27: 51$ & h20v04 & $7: 45: 00$ \\
5 Şubat 2018 & T37SBC (2A) & $8: 22: 51$ & h20v05 & $7: 05: 00$ \\
16 Mart 2018 & T36TUL (2A) & $8: 47: 11$ & h20v04 & $8: 45: 00$ \\
11 Mart 2018 & T38SLH (2A) & $7: 57: 31$ & h21v05 & $8: 30: 00$ \\
12 Ocak 2018 & T38SMJ (2B) & $7: 52: 59$ & h21v05 & $7: 55: 00$ \\
7 Nisan 2018 & T36SVF (2B) & $8: 35: 59$ & h20v05 & $8: 10: 00$ \\
24 Şubat 2018 & T37TFE (2B) & $7: 59: 09$ & h21v05 & $7: 35: 00$ \\
26 Mart 2018 & T38SKH (2B) & $7: 56: 09$ & h21v05 & $7: 45: 00$ \\
24 Şubat 2018 & T38TKK (2B) & 7:59:09 & h21v05 & $7: 35: 00$ \\
\hline
\end{tabular}

T36TTL karosunun durumuna özel olarak bakıldığında, su olan pikseller çıkarıldığında \%21 oranında ormanlık ve $\% 74$ oranında makilik ve karışık tarım arazi sınıflarından oluşmaktadır. Ayrıca bu karoya ait sadece Aralık 2017, Ocak ve Nisan 2018 tarihlerinde alınmış üç adet görüntü olup bunların $R$ değerleri sırasıyla 0,60, 0,92 ve -0,002'dir. Marmara Denizi'nin tam batı ucuna gelen bu karo için (Bkz. Şekil 2) Şekil 6'da verilen haritalara bakıldığında, Aralık ayında çok az kar örtüsü gözlenirken, Nisan ayında ise neredeyse kar pikseli bulunmamaktadır. Bu karoya ait saçılım grafiklerine bakıldığında (Bkz. Şekil 7), Aralık ve Ocak ayındaki Sentinel 2 referanslı EKKA değerlerinin MOD10A1 ürünü tarafından daha düşük tahminlendiği görülmektedir. Nisan ayı içinse, Sentinel 2 referanslı maksimum EKKA değerinin 0,33 olduğu, buna karşılık gelen MOD10A1 EKKA değerlerininse 0,0 olduğu gözlemlenmektedir.

T36TUK karosu incelendiğinde, \%10 oranında ormanlık ve toplamda \%89 oranında çayırlık/çalılık, makilik ve karışık tarım arazi sınıflarından oluştuğu gözlemlenmektedir. Karoya ait Aralık 2017 - Şubat 2018 arasında alınan $R$ değerleri 0,86 - 0,96 arasında olurken, Nisan 2018 görüntüleri için 0,23 - 0,79 olmaktadır. Bu karoya ait Şekil 8'de verilen saçılım grafiklerine bakıldığında, MOD10A1 ürününün Aralık ve Ocak ayı için 0,4'ün üzerindeki EKKA değerlerini biraz düşük tahminlediği görülmekle birlikte referans EKKA değerleriyle uyum içinde olduğu izlenmekte; ancak karın erime dönemine gelen Nisan ayında düşük tahminleme hatasının tüm EKKA aralığında artarak ürünün performansının oldukça azaldığı izlenmektedir. 


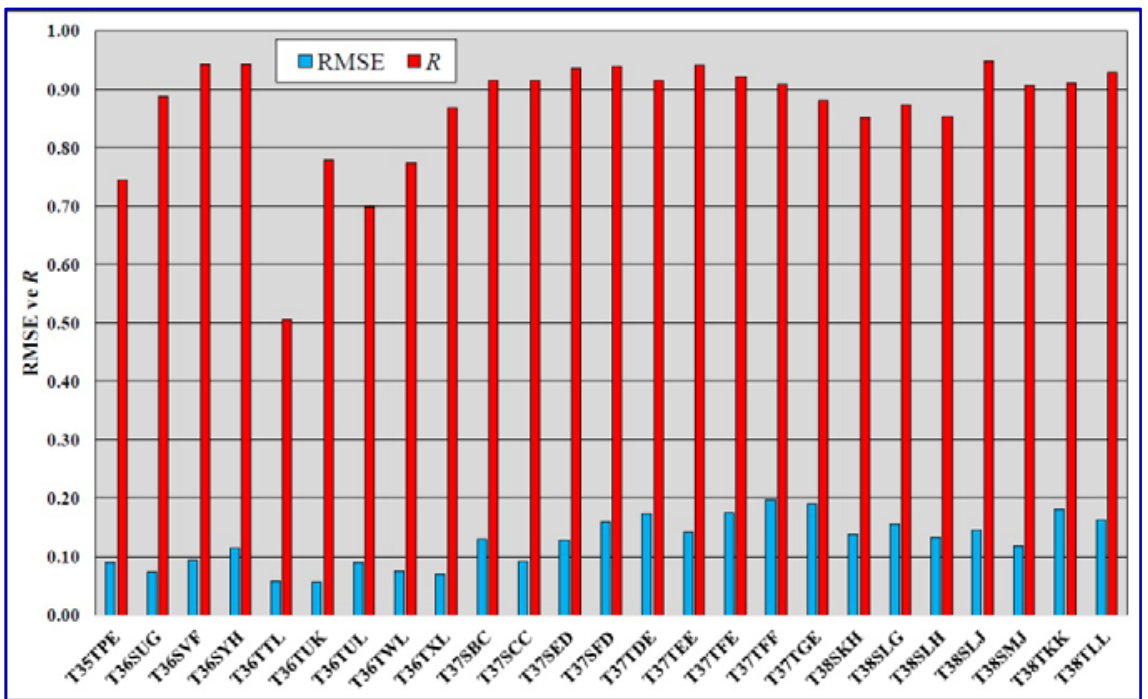

Şekil 5. MOD10A1 için karo bazında ortalama RMSE ve $R$ değerleri.

T36TUL karosu için ormanlık alanlar, su pikselleri çıkarıldıktan sonra, yaklaşık \%42 olurken karonun \%54’ünü makilikler ve karışık tarım arazi sınıfları oluşturmaktadır. Karoya ait 11 ve 16 Aralık 2017, 20 Ocak 2018,16 ve 31 Mart 2018, 5 ve 25 Nisan 2018 tarihlerinden gelen toplam 7 görüntü bulunmakta olup 25 Nisan 2018 görüntüsü tamamen karsızdır. 16 Aralık 2017 görüntüsündeki kar piksellerinin tüm görüntüye oranı (su pikselleri çıkarıldığında) \%0,22 olup karo için $R$ değeri 0,22 olmaktadır. Diğer tarihlerdeki $R$ değerleri 0,70 0,87 aralığındadır.

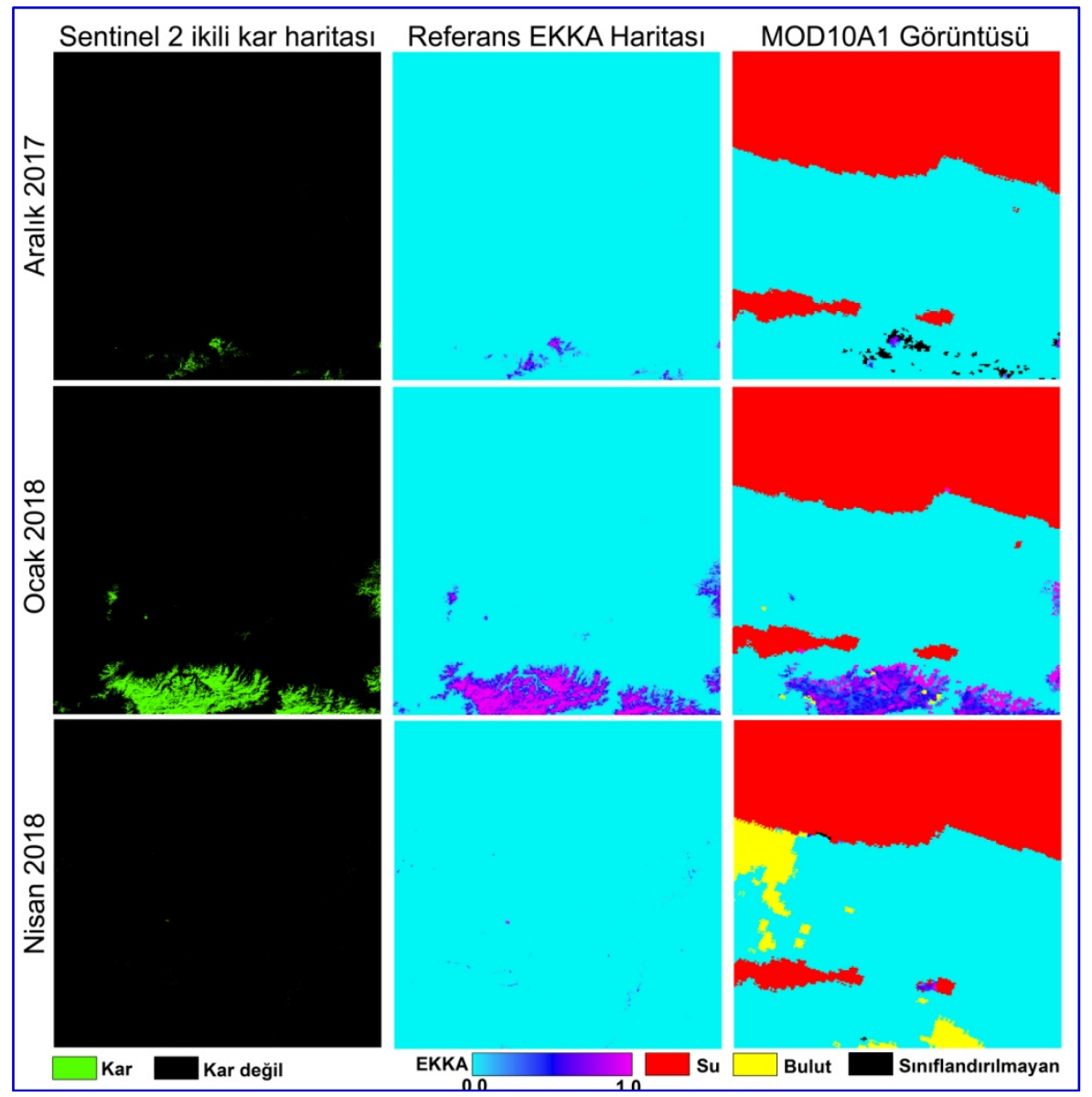

Şekil 6. T36TTL karosu Sentinel 2 ikili kar, referans EKKA ve MOD10A1 görüntüleri. 


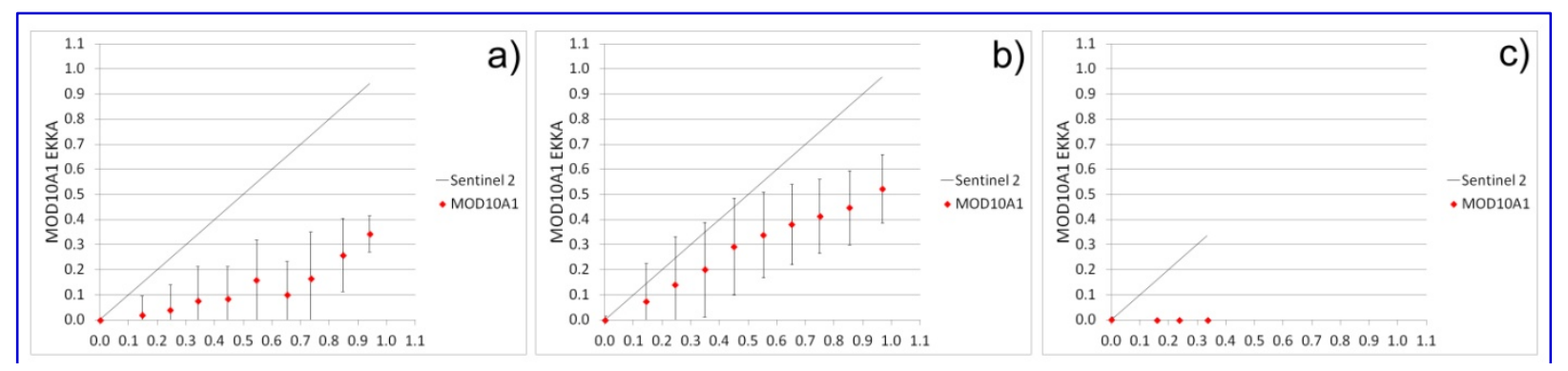

Şekil 7. T36TTL karosu için saçılım grafikleri: a) Aralık 2017, b) Ocak 2018 ve c) Nisan 2018 (Not: Grafikler her bir \%10'luk Sentinel 2 referans EKKA aralı̆ğna karşılık gelen ortalama MOD10A1 EKKA değerlerini standart sapma hata çubuklarıyla göstermektedir).

T36TWL karosu yaklaşık \%17 oranında ormanlık ve toplamda \%83 oranında çayırlık/çalılık, makilik ve karışı tarım arazi sınıflarından oluşmaktadır. Karoya ait Aralık 2017 - Mart 2018 görüntülerinde R değerleri 0,81 0,92 aralı̆̆ında olurken, 10 Kasım 2017 tarihine ait yüksek bulutluluk oranı ve hemen hemen karsız olan görüntü için $R$ değeri 0,12 olarak bulunmuştur. Nisan 2018 için ise $R$ değeri 0,56 olmaktadır.

T35TPE karosu için su pikselleri çıkartıldıktan sonra, karonun \%18'i ormanlık, \%80'i ise çayırlık/çalılık, makilik ve karışık tarım arazi sınıflarından oluşmaktadır. Karoya ait 15, 20 ve 30 Ocak 2018; 11 Mart 2018; 5 Nisan 2018 tarihli görüntülerde $R$ değerleri sırasıyla $0,85,0,89,0,87,0,97$ ve 0,95 olurken, 10 ve 25 Nisan 2018 görüntülerinde 0,45 ve 0,23 değerleriyle düşüş gözlemlenmektedir.

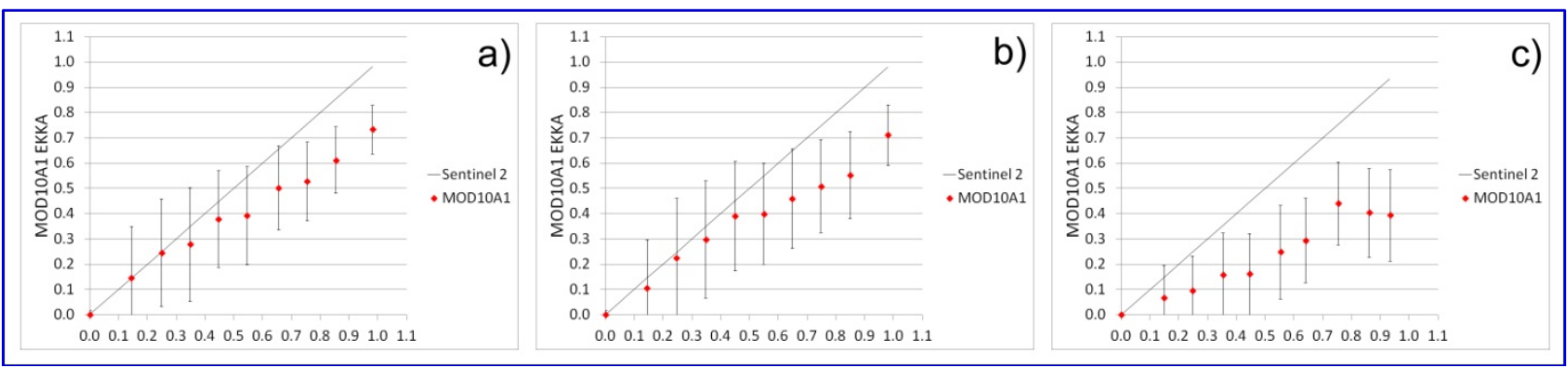

Şekil 8. T36TUK karosu için saçılım grafikleri: a) 13 Aralık 2017, b) 7 Ocak 2018 ve c) 7 Nisan 2018 (Not: Grafikler her bir \%10'luk Sentinel 2 referans EKKA aralı̆̆ına karşılık gelen ortalama MOD10A1 EKKA değerlerini standart sapma hata çubuklarıyla göstermektedir).

MOD10A1 ürününün arazi tipi sınıflarına göre tüm karolar bazında ortalama performans metrikleri Şekil 9'da verilmektedir. MOD10A1 ürününün en düşük performans gösterdiği arazi tipi ormanlık alanlar olup $R$ değerleri $0,56-0,58$ arasında değişmektedir. Ürünün en yüksek performans gösterdiği arazi sınıfı ortalama $R=0,89$ ile çalılıklar/otlaklar olup bunu $0,81,0,78$ ve $0,73 R$ değerleri ile sırasıyla karışık tarım, çorak/seyrek bitki örtüsü ve makilikler takip etmektedir. Normalde ürünün en iyi performans göstermesi beklenen arazi sınıfının çorak/seyrek bitkisi olmasına rağmen bu arazi sınıfı için çalılıklar/otlaklar ve karışık tarım sınıflarına göre daha düşük performans elde edilmesinin bu guruplardaki birden fazla arazi sınıfi dağılımıyla ve topografyanın etkisiyle olduğu düşünülmektedir. Bu çalışmada bulunan MOD10A1 ürünü için arazi örtüsü tipine bağlı performans metrikleri, Kuter vd. (2018)'in aynı ürün için Landsat 8 bazlı referans EKKA haritalarıyla Alpler üzerinde yaptı̆̆ çalışma ile büyük benzerlik göstermektedir. 


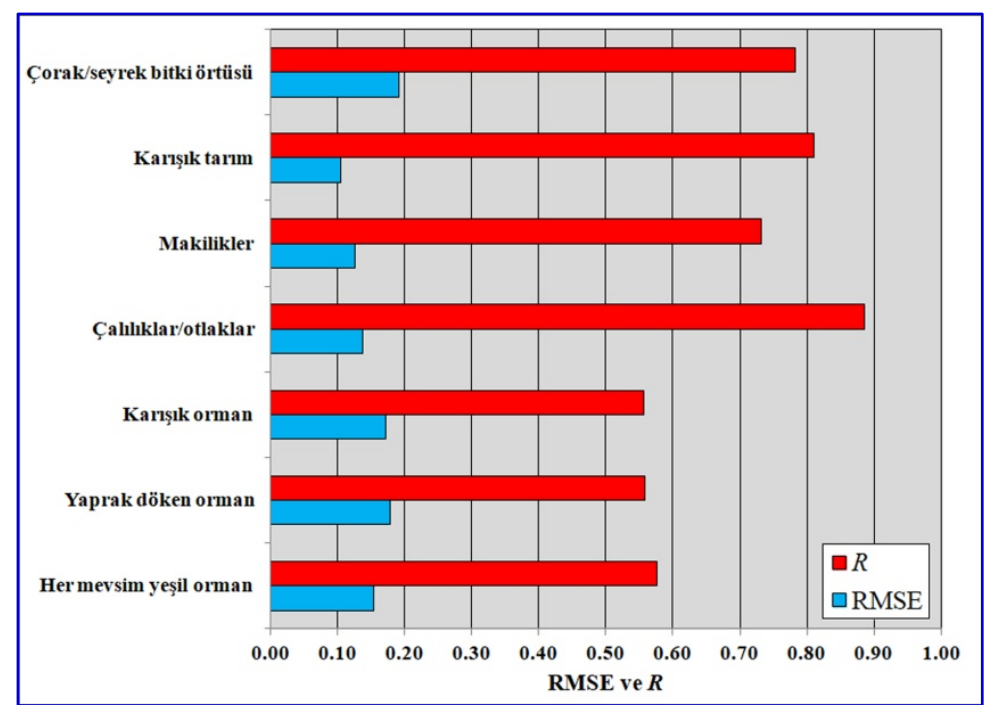

Şekil 9. Arazi tipi sınıfları bazında MOD10A1 için ortalama RMSE ve $R$ değerleri.

\section{Sonuçlar}

Karın mekânsal ve zamansal dağılımının yüksek doğrulukla belirlenmesi, hidrolojik, iklimsel ve diğer bağlantılı çevresel süreçlerin ve bunların değişimlerinin kapsamlı bir şekilde modellenmesi ve anlaşılması için kritik öneme sahiptir. Dolayısıyla, UA yoluyla elde edilen verilerden üretilen kar ürünlerinin ve bunların üretilmesinde kullanılan algoritmaların daha güvenilir ve yüksek doğruluğa sahip hâle getirilmesi için sürekli olarak doğrulama çalışmalarının yapılması bir zorunluluktur.

Günlük olarak küresel ölçekte üretilen bir ürün olan MODIS MOD10A1, hidrolojik ve iklimsel çalışmalar bakımından yüksek zamansal çözünürlüğe ve doğruluğa sahip veri temini açısından önem taşımaktadır. Bu çalışmada, MODIS EKKA ürünü olan MOD10A1'in Türkiye üzerindeki sürekli doğrulama çalışmalarında kullanılmak üzerine Sentinel 2 görüntülerinin uygunluğu tespit edilerek, 2017-2018 kar sezonu için MOD10A1 ürününün Sentinel 2 tabanlı referans EKKA verisiyle doğrulaması yapılmıştır.

Sentinel 2 görüntülerinden ikili kar haritalarının elde edilmesinde kullanılan üç algoritmanın da yüksek POD ve ACC (POD $\geq 0,86$, ACC $\geq 0,82$ ), düşük FAR (FAR $\leq 0,08$ ) değerleriyle yer verisiyle yüksek uyum içinde olduğu gözlemlenmiştir. Toplamda 206 adet karo üzerinde Sentinel 2 ikili kar haritalarından edilen referans EKKA haritalarıyla MODIS MOD10A1 ürününün 2017-2018 kar sezonunda doğrulama çalışmaları yapılmış, MOD10A1 ürününün genel, ay, karo ve arazi tipi bazında performansı incelenmiştir. Bu çalışmada elde edilen sonuçlar, Sentinel 2 görüntülerinin orta/düşük çözünürlükteki uydu kar ürünlerinin ve kar algılama algoritmalarının geliştirilmesine yönelik olarak yürütülen sürekli doğrulama çalışmaları için uygun bir referans veri kaynağı olduğunu ortaya koymaktadır. Ayrıca, yüksek zamansal çözünürlüğe sahip küresel MODIS MOD10A1 kar ürününün 2017-2018 Türkiye kar sezonu için Sentinel 2 bazlı referans veriyle karşılaştırıldığında oldukça yüksek doğruluğa sahip olduğu görülmekle birlikte, ormanlık alanlarda ve karın erime dönemlerinde ürünün doğruluğunda düşüş olduğu tespit edilmiştir.

MOD10A1 ürününün karşılaştırmanın yapıldığı Sentinel 2 karolar üzerinde genel olarak $R \geq 0,80$ ve RMSE $\leq$ 0,20 değerleri ile oldukça iyi performans sergilediği görülmektedir. Bununla birlikte ürünün ormanlık alanlarda gösterdiği düşük doğruluk beklenen bir durum olup bu arazi sınıfı için elde edilen düşük $R$ değerleriyle de $(\sim 0,56)$ görülmektedir. Bununla birlikte, ileride daha fazla kilit konunun ele alınması gerekmektedir. Öncelikle, MOD10A1 ürününün değerlendirilmesinde arazi sınıflarının yanı sıra topografyanın (yükseklik, eğim, bakı) da etkisinin araştırılarak daha detaylı bir analiz yapılması öngörülmektedir. Ayrıca, farklı referans kar ürünleri üretilmesinde kullanılan algoritmalarla yapılacak karşılaştırmalı bir çalışma, Sentinel 2 görüntülerinden elde edilen kar haritalarının güvenilirliğini değerlendirilmesine katkı sağlayacaktır. Bulutluluk oranının üretilen referans kar haritalarının doğruluğu üzerindeki etkisinin farklı bulutluluk oranlarına sahip görüntülerin analizi yoluyla daha ayrıntılı şekilde araştırılması da ileride yürütülmesi planlanan çalışma aşamalarından birisidir. 


\section{Bilgilendirme}

Bu çalışma Uğur TUTTU'nun yüksek lisans tezinden üretilmiştir. Bu çalışmada EUMETSAT H-SAF projesi kapsamında MGM tarafından sağlanan KD ölçümleri kullanılmıştır.

\section{Kaynaklar}

1. Appel, I. (2018). Uncertainty in satellite remote sensing of snow fraction for water resources management. Frontiers of Earth Science, 12(4): 711-727.

2. Crawford, C. J. (2015). MODIS Terra Collection 6 fractional snow cover validation in mountainous terrain during spring snowmelt using Landsat TM and ETM+. Hydrological Processes, 29(1): 128-138.

3. Dong, J., Peters-Lidard, C. (2010). On the Relationship Between Temperature and MODIS Snow Cover Retrieval Errors in the Western U.S. IEEE Journal of Selected Topics in Applied Earth Observations and Remote Sensing, 3(1): 132-140.

4. Doswell III, C. A., Davies-Jones, R., Keller, D. L. (1990). On summary measures of skill in rare event forecasting based on contingency tables. Weather and forecasting, 5(4): 576-585.

5. Dwyer, J., Schmidt, G. (2006). The MODIS Reprojection Tool. In J. J. Qu, W. Gao, M. Kafatos, R. E. Murphy ve V. V. Salomonson (Eds.), Earth Science Satellite Remote Sensing: Vol. 2: Data, Computational Processing, and Tools (162-177). Berlin, Heidelberg: Springer Berlin Heidelberg.

6. Frei, A., Tedesco, M., Lee, S., Foster, J., Hall, D. K., Kelly, R., Robinson, D. A. (2012). A review of global satellite-derived snow products. Advances in Space Research, 50(8): 1007-1029.

7. Friedl, M. A., Sulla-Menashe, D., Tan, B., Schneider, A., Ramankutty, N., Sibley, A., Huang, X. (2010). MODIS Collection 5 global land cover: Algorithm refinements and characterization of new datasets. Remote Sensing of Environment, 114(1): 168-182.

8. Gatti, A., Galoppo, A. (2018). Sentinel-2 Products Specification Document (Issue: 14.5). Thales Alenia Space. WEB, https://sentinel.esa.int/documents/247904/685211/Sentinel-2-Products-SpecificationDocument (20.01.2019).

9. Hall, D., Foster, J., Verbyla, D., Klein, A., Benson, C. (1998). Assessment of snow-cover mapping accuracy in a variety of vegetation-cover densities in central Alaska. Remote Sensing of Environment, 66(2): 129-137.

10. Hall, D. K., Martinec, J. (1985). Remote Sensing of Ice and Snow. USA: Chapman and Hall.

11. Hall, D. K., Riggs, G. A., Salomonson, V. V. (1995). Development of Methods for Mapping Global Snow Cover Using Moderate Resolution Imaging Spectroradiometer Data. Remote Sensing of Environment, 54: 127-140.

12. Hall, D. K., Riggs, G. A., Salomonson, V. V., DiGirolamo, N. E., Bayr, K. J. (2002). MODIS snowcover products. Remote Sensing of Environment, 83: 181-194.

13. Hüsler, F., Jonas, T., Wunderle, S., Albrecht, S. (2012). Validation of a modified snow cover retrieval algorithm from historical 1-km AVHRR data over the European Alps. Remote Sensing of Environment, 121: 497-515.

14. Klein, A. G., Barnett, A. C. (2003). Validation of daily MODIS snow cover maps of the Upper Rio Grande River Basin for the 2000-2001 snow year. Remote Sensing of Environment, 86(2): 162-176.

15. Kuter, S., Akyurek, Z., Weber, G. W. (2018). Retrieval of fractional snow covered area from MODIS data by multivariate adaptive regression splines. Remote Sensing of Environment, 205: 236-252.

16. López-Moreno, J. I., Fassnacht, S .R., Heath, J. T., Musselman, K. N., Revuelto, J., Latron, J., Morán-Tejeda, E., Jonas, T. (2013). Small scale spatial variability of snow density and depth over complex alpine terrain: Implications for estimating snow water equivalent. Advances in Water Resources, 55: 40-52.

17. Louis, J. (2018). Sentinel-2 S2 MPC L2A Product Definition Document, WEB, https://sentinels.copernicus.eu/documents/247904/685211/S2+L2A+Product+Definition+Document/2c0f6d 5f-60b5-48de-bc0d-e0f45ca06304 (25.07.2019).

18. Louis, J., Debaecker, V., Pflug, B., Main-Korn, M., Bieniarz, J., Mueller-Wilm, U., Cadau, E., Gascon, F. (2016). Sentinel-2 Sen2Cor: L2A Processor for Users, Living Planet Symposium, 9-13 May 2016, Prague, Czech Republic.

19. Marchane, A., Jarlan, L., Hanich, L., Boudhar, A., Gascoin, S., Tavernier, A., Filali, N., Le Page, M., Hagolle, O., Berjamy, B. (2015). Assessment of daily MODIS snow cover products to monitor snow cover dynamics over the Moroccan Atlas mountain range. Remote Sensing of Environment, 160: 72-86.

20. Metsämäki, S., Ripper, E., Mattila, O.-P., Fernandes, R., Bippus, G., Luojus, K., Nagler, T., Bojkov, B. (2016). Evaluation of Northern Hemisphere Snow Extent products within ESA SnowPEx-project, IEEE International Geoscience and Remote Sensing Symposium (IGARSS 2016), Beijing, China. 
21. Parajka, J., Blöschl, G. (2006). Validation of MODIS snow cover images over Austria. Hydrology and Earth System Sciences Discussions, 3(4): 1569-1601.

22. Parajka, J., Blöschl, G. (2008). Spatio-temporal combination of MODIS images-potential for snow cover mapping. Water Resources Research, 44(3): 1-13.

23. Parajka, J., Holko, L., Kostka, Z., Blöschl, G. (2012). MODIS snow cover mapping accuracy in a small mountain catchment-comparison between open and forest sites. Hydrology and Earth System Sciences 16(7): 2365-2377.

24. Parajka, J., Pepe, M., Rampini, A., Rossi, S., Blöschl, G. (2010). A regional snow-line method for estimating snow cover from MODIS during cloud cover. Journal of Hydrology, 381(3-4): 203-212.

25. Pirazzini, R., Leppänen, L., Picard, G., Lopez-Moreno, J., Marty, C., Macelloni ,G., Kontu. A., von Lerber, A., Tanis, C., Schneebeli, M. J. S. (2018). European in-situ snow measurements: Practices and purposes, 18(7): 2016.

26. Poon, S. K., Valeo, C. (2006). Investigation of the MODIS snow mapping algorithm during snowmelt in the northern boreal forest of Canada. Canadian Journal of Remote Sensing, 32(3): 254-267.

27. Raleigh, M. S., Livneh, B., Lapo, K., Lundquist, J. D. (2016). How Does Availability of Meteorological Forcing Data Impact Physically Based Snowpack Simulations? Journal of Hydrometeorology, 17(1): 99120.

28. Riggs, G. A., Hall, D. K. (2016). MODIS/Terra Snow Cover Daily L3 Global 500m Grid, Version 6. National Snow and Ice Data Center Distributed Active Archive Center, WEB, https://nsidc.org/data/MOD10A1/versions/6 (24.09.2019).

29. Riggs, G. A., Hall, D. K., Román, M. O. (2016). MODIS Snow ProductsCollection 6 User Guide Version 1.0, WEB, https://modis-snow-ice.gsfc.nasa.gov/uploads/C6_MODIS_Snow_User_Guide.pdf (04.02.2019).

30. Rodell, M., Houser, P. (2004). Updating a land surface model with MODIS-derived snow cover. Journal of Hydrometeorology, 5(6): 1064-1075.

31. Salomonson, V. V., Appel, I. (2004). Estimating fractional snow cover from MODIS using the normalized difference snow index. Remote Sensing of Environment, 89: 351-360.

32. Salomonson, V. V., Appel, I. (2006). Development of the Aqua MODIS NDSI Fractional Snow Cover Algorithm and Validation Results. IEEE Transactions on Geoscience and Remote Sensing, 44: 1747-1756.

33. Shamir, E., Georgakakos, K. P. (2006). Distributed snow accumulation and ablation modeling in the American River basin. Advances in Water Resources, 29(4): 558-570.

34. Şorman, A., Akyürek, Z., Şensoy, A., Şorman, A., Tekeli, A. (2007). Commentary on comparison of MODIS snow cover and albedo products with ground observations over the mountainous terrain of Turkey. Hydrology and Earth System Sciences, 11(4): 1353-1360.

35. Sürer, S., Akyürek, Z. (2012). Evaluating the utility of the EUMETSAT HSAF snow recognition product over mountainous areas of eastern Turkey. Hydrological Sciences Journal, 57(8): 1684-1694.

36. Tekeli, A. E., Akyürek, Z., Şorman, A. A., Şensoy, A., Şorman, Ü. (2005). Using MODIS snow cover maps in modeling snowmelt runoff process in the eastern part of Turkey. Remote Sensing of Environment, 97: 216-230.

37. URL-1. (2008). Guide to Meteorological Instruments and Methods of Observation. World Meteorological Organisation, WEB, https://library.wmo.int/pmb_ged/wmo_8_en-2012.pdf (22.02.2019).

38. Vermote, E. F., Kotchenova, S. Y., Ray, J. P. (2011). MODIS surface reflectance user's guide - Version 1.3. MODIS Land Surface Reflectance Science Computing Facility, WEB, http://modissr.Itdri.org/guide/MOD09_UserGuide_v1.4.pdf (24.09.2019).

39. Viviroli, D., Archer, D. R., Buytaert, W., Fowler, H. J., Greenwood, G. B., Hamlet, A. F., Huang, Y., Koboltschnig, G., Litaor, M. I., López-Moreno, J. I., Lorentz, S., Schädler, B., Schreier, H., Schwaiger, K., Vuille, M., Woods, R. (2011). Climate change and mountain water resources: overview and recommendations for research, management and policy. Hydrology and Earth System Sciences, 15(2): 471-504.

40. Wang, X., Xie, H., Liang, T. (2008). Evaluation of MODIS snow cover and cloud mask and its application in Northern Xinjiang, China. Remote Sensing of Environment, 112(4): 1497-1513.

41. Wang, X., Xie, H., Liang, T., Huang, X. (2009). Comparison and validation of MODIS standard and new combination of Terra and Aqua snow cover products in northern Xinjiang, China. Hydrological Processes: An International Journal, 23(3): 419-429. 